\title{
Muscle strength and inflammatory response to the training load in rowers
}

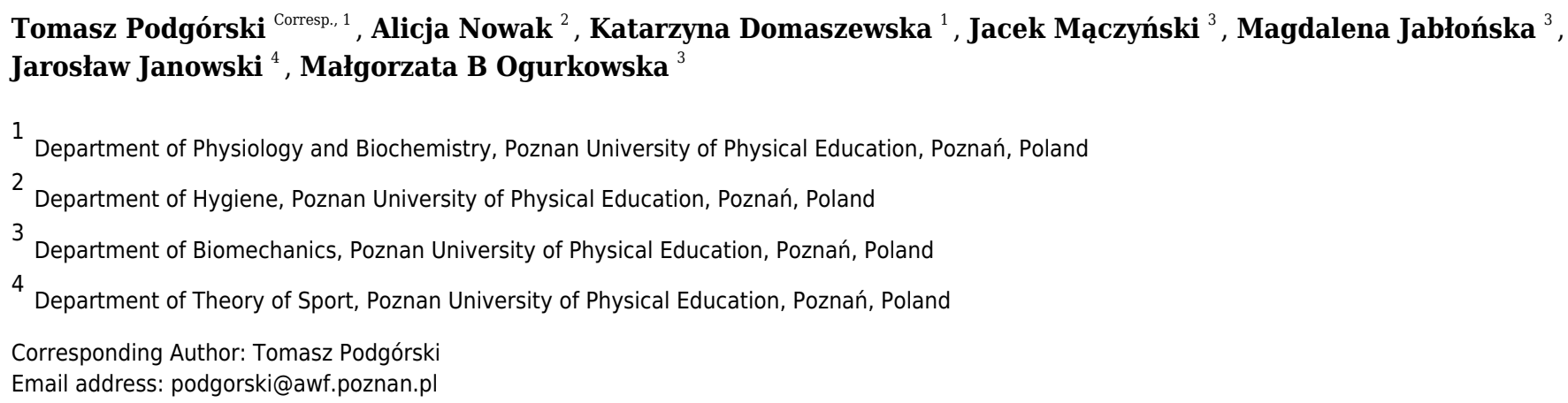

Background. Regular exercise leads to changes in muscle metabolism. The consequence of this is the adaptation to higher training loads. The aim of this study was to evaluate biomechanical and biochemical parameters describing the functions of skeletal muscles in periods when changes in training forms were introduced.

Methods. Seventeen male sweep-oar rowers, members of the Polish national rowing team, participated. The study was carried out at the beginning and at the end of the preparatory period. In the first and second examination measurements of torques of selected muscle groups and blood biochemical analysis were performed.

Results. There was observed a statistically significant decrease in the relative global force of the right lower limb between both terms of examination. A statistically significant increase in maximum torque was found for torso flexors. In the case of muscles responsible for torso rotation, a statistically significant decrease in the torque values of right torso rotators was observed. A significant difference with respect to creatine kinase activity, total testosterone concentration, total testosterone to cortisol ratio and total phenolics concentration $(p<0.05)$.

Conclusion. The study shows that the rowers' training should be more focused on building the strength of lower limbs to prevent the overload of lumbar spine and that the amount of force developed may be significantly affected by the antioxidant potential of rowers. 
1 Muscle Strength And Inflammatory Response To The 2 Training Load In Rowers

3

4

5

Tomasz Podgórski ${ }^{1}$, Alicja Nowak ${ }^{2}$, Katarzyna Domaszewska ${ }^{1}$, Jacek Mączyński ${ }^{3}$, Magdalena Jabłońska $^{3}$, Jarosław Janowski ${ }^{4}$, Małgorzata B. Ogurkowska ${ }^{3}$

${ }^{1}$ Department of Physiology and Biochemistry, Poznan University of Physical Education, Poznań, Poland

2 Department of Hygiene, Poznan University of Physical Education, Poznań, Poland

${ }^{3}$ Department of Biomechanics, Poznan University of Physical Education, Poznan, Poland

${ }^{4}$ Department of Theory of Sport, Poznan University of Physical Education, Poznań, Poland

Corresponding Author:

Tomasz Podgórski ${ }^{1}$

Królowej Jadwigi 27/39, Poznań, 61-871, Poland

Email address: podgorski@awf.poznan.pl

\section{Abstract}

Background. Regular exercise leads to changes in muscle metabolism. The consequence of this is the adaptation to higher training loads. The aim of this study was to evaluate biomechanical and biochemical parameters describing the functions of skeletal muscles in periods when changes in training forms were introduced.

Methods. Seventeen male sweep-oar rowers, members of the Polish national rowing team, participated. The study was carried out at the beginning and at the end of the preparatory period. In the first and second examination measurements of torques of selected muscle groups and blood biochemical analysis were performed.

Results. There was observed a statistically significant decrease in the relative global force of the right lower limb between both terms of examination. A statistically significant increase in maximum torque was found for torso flexors. In the case of muscles responsible for torso rotation, a statistically significant decrease in the torque values of right torso rotators was observed. A significant difference with respect to creatine kinase activity, total testosterone concentration, total testosterone to cortisol ratio and total phenolics concentration $(p<0.05)$. Conclusion. The study shows that the rowers' training should be more focused on building the strength of lower limbs to prevent the overload of lumbar spine and that the amount of force developed may be significantly affected by the antioxidant potential of rowers.

\section{Introduction}

Rowing training is a significant load on the organism due to a high volume and intensity of training sessions, especially during the preparatory period. Studies conducted by some authors 
41 among well-trained rowers showed an increase in fatigue in certain training periods (Woods et

42

43

44

45

46

47

48

49

50

51

52

53

54

55

56

57

58

59

60

61

62

63

64

65

66

67

68

69

70

71

72

73

74

75

76

77

78

79

80 high-performance rowers engage about $70 \%$ of all the muscles when rowing a boat (Richter et al., 2010).

Correctly planned sports training sessions result in adaptive changes in muscle tissue, which consist among other things in the improvement of metabolic processes and changes in muscle structure. These changes cause an increase in muscle strength and/or increased resistance of muscle tissue to fatigue (Egan and Zierath, 2013). This process involves, among others, oxygen free radicals (reactive oxygen species, ROS) generated during physical activity (Steinbacher and Eckl, 2015), growth factors and inflammatory agents resulting from muscle fibre damage. (Sass et al., 2018; Yang and $\mathrm{Hu}, 2018$ ). The number of granulocytes, monocytes and lymphocytes in the circulatory system increases and so does the concentration of some inflammatory factors e.g., interleukin 6 (IL-6) and acute phase proteins such as C-reactive protein (CRP) (Pedersen and Hoffman-Goetz, 2000; Sass et al., 2018).

Growth factors, free radicals and cytokines produced in damaged skeletal muscles initiate repair processes. However, with very intensive workouts, there may be an imbalance between these processes (Steinbacher and Eckl, 2015; Tidball, 2005). Systemic factors which are modified by physical activity, such as some hormones (testosterone, cortisol), endogenous and exogenous antioxidants or metabolic factors involved in myocyte energy metabolism, also play an important role in the mechanism regulating the function and structure of skeletal muscles (Jensen et al., 2011; Pedersen and Hoffman-Goetz, 2000; Steinbacher and Eck1, 2015).

Testosterone is the basic hormone involved in maintaining skeletal muscle structure and the related muscle strength. In the cardiovascular system there is mainly testosterone bound to specific proteins (SHBG, sex hormone binding globulin) and free testosterone. Both of these forms take part in the synthesis of muscle proteins (Griggs et al., 1989). Furthermore, testosterone activates the glucose metabolism-related signalling pathway in skeletal muscle cells via regulation of glucose transporter-4 (GLUT-4), which plays an important role in supplying skeletal muscles with energy substrates when the muscles are working (Sato et al., 2008). Observation of parameters characterizing the functional state of skeletal muscles, including the strength of selected muscle groups or particular biochemical indices, allows to evaluate the athletes' degree of training adaptation. Skeletal muscle strength is most frequently assessed in isometric tests (Hughes et al., 1999; Janiak et al., 1993; Sterkowicz et al., 2018) and isokinetic tests (Buśko et al., 2018; Calmels et al., 1997), depending on the study objective. Isometric and isokinetic muscle diagnostic tests were performed for the purposes of the study of overloading of the spine and joints caused by muscle strength deficits (Diamond et al., 2016; Kocjan, and Sarabon, 2014; McGregor et al., 2004). Comparative analysis of muscle strength topography for the studied groups allows to define the risk of sustaining musculoskeletal injuries (Diamond et al., 2016; McGregor et al., 2004).

Due to the occurrence of frequent musculoskeletal injuries among professional rowers, in particular affecting the spine, the aim of this study was to evaluate biomechanical and

Peer) reviewing PDF | (2020:08:51684:1:0:NEW 11 Oct 2020) 
81 biochemical parameters describing the functions of skeletal muscles in periods when changes in

82

83

84

85

86

87

88

89

90

91

92

93

94

95

96

97

98

99

100

101

102

103

104

105

106

107

108

109

110

111

112

113

114

115

116

117

118

119

120

training forms were introduced. Discovering the pathobiomechanism of overload changes of the motor system in this group of athletes may allow to modify the training scheme, thereby leading to a reduction in injuries.

\section{Materials \& Methods}

\section{Participants}

Initially, the study included 23 male sweep-oar rowers. A total of 17 subjects qualified for the study after excluding athletes who were injured, those who were taking anti-inflammatory drugs and those who did not fulfill the conditions of the study protocol (e.g. non fasting). The studied athletes were members of the Polish national rowing team who participate in major international competitions (World Championships, European Championships, Olympic Games). The study were carried out in two terms of the rowing training cycle: at the beginning (November) and at the end (March/April) of the preparatory period. The study was approved by the Regional Bioethics Committee at Poznan University of Medical Sciences (No. 208/17). Each of the athletes, having familiarized themselves with the study protocol, agreed in writing to participate in the study.

\section{Anthropometrics measurements}

Body composition was measured in the first and second examination, with the use of the Tanita BC-418 MA analyser (Japan) with the subjects barefoot and wearing their underclothes. Body height was measured with the use of the WPT $60 / 150$ OW medical scales (Radwag ${ }^{\circledR}$, Poland).

\section{Biomechanics measurements}

Biomechanical measurements of selected muscle groups were performed with the use of two devices; the first was produced by JBA Zb. Staniak (Poland) and was equipped with torque gauges with a relative measurement error of less than $0.5 \%$ (Figure 1 and 2) and the second served to measure the global extension force of the lower limbs (Figure 3). This device was equipped with a Scaime SB30X dynamometer (relative force measurement error of $\pm 0.017 \%$ ) and a PUE 1 gauge (Radwag ${ }^{\circledR}$, Poland).

The global force of lower limbs extensors is the resultant force generated simultaneously by extensors of hip, knee and ankle joints. Lower limb were measured asymmetrically, i.e.

alternately left/right limb, respectively.

The construction of the devices ensures optimal stabilization of the limbs and torso and the possibility of taking measurements in body positions which are normally subject to measurement in biomechanical laboratories. The global force of lower limb extensors 14 and torque of flexors, extensors and torso rotators under static conditions triggered in 1.5-3.0 s. were recorded. Each type of measurement was repeated 3 times. The final result was the highest of the 3 recorded values of force or torque, normalized to body weight. 
121

122

123

124

125

126

127

128

129

130

131

132

133

134

135

136

137

138

139

140

141

142

143

144

145

146

147

148

149

150

151

152

153

154

155

156

157

158

159

160

--- Figures 1, 2, 3 near here ---

\section{Blood collection and biochemical measurements}

The athletes did not train on the day preceding the blood test. Blood samples were taken from the ulnar vein using a S-Monovette syringe tube (SARSTEDT, Germany), then placed in tubes containing a clot activator, and centrifuged $\left(1500 \mathrm{~g}, 4^{\circ} \mathrm{C}, 4\right.$ minutes $)$ in order to separate the serum. The samples were frozen and stored at $-75^{\circ} \mathrm{C}$ until the time the analyses were performed. Creatine kinase $(\mathrm{CK})$ activity and glucose concentration were determined with the use of the Accent 200S (Cormay, Poland) biochemical analyser and sets of enzymatic reagents (Cormay, Poland); the sensitivity of the sets was $7.4 \mathrm{U} / \mathrm{L}$ and $2.2 \mathrm{mg} / \mathrm{dL}$, respectively. The concentrations of total testosterone (TT) and free testosterone (FT), cortisol (C), high-sensitivity C-reactive protein (hsCRP), insulin (DRG Instruments GmbH, Germany) and interleukin 6 (IL-6, AssayPro LLC, St. Charles, MO) were measured with the use of the ELISA immunoenzymatic method. The sensitivity of the ELISA kits was as follows: $0.083 \mathrm{ng} / \mathrm{mL}, 0.04 \mathrm{pg} / \mathrm{mL}, 2.5 \mathrm{ng} / \mathrm{mL}, 0.1$ $\mathrm{mg} / \mathrm{L}, 1.76 \mu \mathrm{l} / \mathrm{mL}, 0.007 \mathrm{ng} / \mathrm{mL}$, respectively. Insulin sensitivity was expressed as a QUICKI (Quantitative Insulin Sensitivity Check Index) value and was calculated using the following formula: $1 / \log$ insulin $+\log$ glycemia in $\mathrm{mg} / \mathrm{dL}$ (Katz et al., 2000).

Colometric methods were used to determine the concentrations of the total antioxidant capacity of plasma (Ferric Reducing Ability of Plasma, FRAP, reference values: 600-1600 $\mu \mathrm{mol} / \mathrm{L}$ ) (Benzie and Strain, 1966), the plasma concentration of thiobarbituric acid reactive substances (TBARS, reference values: 1-6 $\mathrm{mol} / \mathrm{L}$ ) (Ohkawa et al., 1979) and total phenolics (reference values: 2.8-4.0 g/L) (Singleton and Rossi, 1965).

\section{Training program}

The training loads during the preparatory period are listed in Table 1. The loads were highly varied in terms of their direction and training modalities applied. The standard number of training sessions was from 9 to 10 during the preparatory period and from 12 to 14 during training camps. At the beginning of the preparatory period, general training sessions were prevailing with training modalities such as: running, proprioceptive exercises, swimming, cycling, cross-country skiing, team sports and strength training. Targeted training, i.e. rowing on a indoor rower, was included beginning with microcycle 5. Specialised exercises on water were included from microcycle 17 and the amount of such training increased dynamically in subsequent microcycles.

At the beginning of the preparatory period (microcycles 1 to 4), there were mainly low and moderate intensity aerobic exercises and muscle mass building strength training. In the next mesocycle (microcycles 5 to 8) the intensity of exercises increased, the aim being to develop aerobic endurance, aerobic and anaerobic endurance and maximum strength. This trend continued in the next mesocycle (microcycles 9 to 12), however, with a significant increase in aerobic-anaerobic loads ( 2 sessions in the microcycle). Power developing sessions were also 
161 introduced. In microcycles 13 to 24 the development of aerobic and aerobic-anaerobic endurance

162

163

164

165

166

167

168

169

170

171

172

173

174

175

176

177

178

179

180

181

182

183

184

185

186

187

188

189

190

191

192

193

194

195

196

197

198

199

200

continued and sessions increasing anaerobic endurance were introduced. In strength training, power training continued and strength conditioning components were included. The detailed training programme is presented in Table 1.

--- Table 1 near here ---

\section{Statistical analysis}

All data are presented as mean, standard deviation (SD) and median values and interquartile range. The normality of distribution was tested with the Shapiro-Wilk test. The differences between paired and normally distributed variables were investigated using the $T$-test and the Wilcoxon test was used for non-normally distributed variables. The Pearson analysis for normally distributed variables and Spearman's rank analysis for non-normally distributed variables were used to calculate correlation coefficients. The level of statistical significance was set at $\mathrm{p}<0.05$. The obtained results were analysed statistically using the Dell Inc. (2016) Dell Statistica 13 software (Tulsa, Oklahoma, USA).

\section{Results}

There was no significant difference between the first and second examination with respect to the somatic features of the rowers (Table 2).

--- Table 2 near here ---

With respect to biomechanical indices (Table 3), a statistically significant decrease in the relative global force of the right lower limb from the beginning to the end of the preparatory period was observed (mean value decreased by $2.7 \mathrm{~N} / \mathrm{kg}$ ). In the case of the lower left limb there was a tendency for similar changes $(\mathrm{p}=0.09)$ (mean value decreased by $2.0 \mathrm{~N} / \mathrm{kg}$ ).

However, taking into account the group of torso muscles, a statistically significant increase in maximum torque between the first and second examination (Table 3) was found for torso flexors (mean value increase of $0.36 \mathrm{Nm} / \mathrm{kg}$ ). In the case of extensors there was a tendency towards change ( $\mathrm{p}=0.09$ ) (increase by $0.39 \mathrm{Nm} / \mathrm{kg}$ ). In the case of muscles responsible for torso rotation, a statistically significant decrease in the torque values of right torso rotators was observed between the two examinations (decrease in mean value by $0.09 \mathrm{Nm} / \mathrm{kg}$ ). There were no significant changes between the study of other biomechanical parameters.

--- Table 3 near here ---

A comparative analysis of the biochemical indices (Table 4) measured showed a significant difference with respect to CK, TT, TT/C and total phenolics ( $\mathrm{p}<0.05)$. 
201

202

203

204

205

206

207

208

209

210

211

212

213

214

215

216

217

218

219

220

221

222

223

224

225

226

227

228

229

230

231

232

233

234

235

236

237

238

239

240

--- Table 4 near here ---

In the first examination, the correlation analysis showed relationships between the concentration of total phenolics and the global strength of extensors of the left lower limb $(\mathrm{r}=$ $0.54, p=0.026)$ and the right lower $\operatorname{limb}(r=0.61, p=0.009$, Figure $4 A)$ and the torque of right torso rotators $(\mathrm{r}=0.51, \mathrm{p}=0.035$, Figure $4 \mathrm{~B})$. The fat mass correlated with the QUICKI index ( $\mathrm{r}$ $=0.55, \mathrm{p}=0.023)$.

Changes $\left(\Delta_{\mathrm{II}-\mathrm{I}}\right)$ in TT concentration between the two examinations correlated with insulin ( $\mathrm{r}=$ $0.54, p=0.026)$ and glucose $(r=-0.52, p=0.032)$ concentrations in the second examination, and the change $\left(\Delta_{\mathrm{II}-\mathrm{I}}\right)$ in the trunk extensors torque correlated with the TT/C ratio $(\mathrm{r}=-0.50, \mathrm{p}=$ $0.042)$ and FT/C $(r=-0.50, p=0.042)$ in the second examination (Figure $4 \mathrm{C}$ ).

--- (Figure 4 A, B, C near here) ---

\section{Discussion}

This study presents the effect of intense rowing training in the preparatory period on selected indicators of muscle damage and muscle tissue repair mechanisms. A specific change in biomechanical parameters describing the strength of selected groups of muscles of the torso and lower extremities was observed. A decrease in the relative global force of extensors of the lower extremities was observed with a significant change in the right extremity. The mean global force of the extensors decreased by $9.7 \%$ for the right lower limb and by $7.1 \%$ for the left lower limb. In terms of the torso, there was a significant increase in the torque of flexor muscles $(9.3 \%$ on average) and a tendency towards changes in rectifiers (by $4.9 \%$ ). In the analysed period of the training cycle the opposite effect should be expected. Namely, at the end of the preparatory period, lower limb extensor muscles, which are most involved in the pulling phase in the rowing cycle should definitely become stronger compared to the beginning of the preparatory period. The results are probably related to the fact that at the beginning of the preparatory period (weeks 1 to 4 ) the athletes underwent strength training with a particular emphasis on the mass and strength of the lower limbs (see training description, Table 1). This kind of training was absent in the subsequent stages of the preparatory period and was replaced by exercises on indoor rowers and rowing the boat in natural conditions, i.e. on the water. This type of training entails a change in the load on the lower limbs and skeletal muscles of the torso are involved to a large extent; they become stiffened over time, which reduces their ability to reach maximum torques, i.e. they become overloaded. The above phenomenon concerns mainly extensor muscles which - in the case of inadequately trained lower limb muscles - are engaged to generate the force necessary to propel the boat (Ogurkowska et al., 2015). The above fact confirms one of the findings of the study, i.e. that the increase in torso torque was much smaller in the case of extensor muscles than flexor muscles.

There was also a decrease in the values of torso torque between the first and second examination (mean values decreased by $7.5 \%$ for the right rotator and by $9.3 \%$ for the left rotator). The 
241 technique of rowing with sweep oars requires asymmetrical work, especially when the water is

242 "catching" the blade, during which the body rotates towards the outrigger, so that the shoulders

243 are as parallel to the oar as possible. The inner shoulder is lowered due to the need to rotate the

244 body, while the outer shoulder is slightly higher. This means that while rowing, the torso

245 rotators, as well as flexors and extensors, are overloaded, even more so after prolonged training.

246 It should be assumed that this is the case during the second half of the analysed period of the

247 training cycle, which focuses primarily on the indoor rower and boat. It was noted that during a

248 maximal rowing trial on the indoor rower, lumbar flexion may increase from $75 \%$ to $90 \%$ of the

249

250

251

252

253

254

255

256

257

258

259

260

261

262

263

264

265

266

267

268

269

270

271

272

273

274

275

276

277

278

279 maximum range of motion, most likely due to muscle fatigue (Ogurkowska, 2007). The load on the rotator muscles leads to their stiffening and, at the same time, to a reduction in the values of torque they reach. It should be emphasized that the obtained results may be indicative of the pathobiomechanism of overload changes in the lumbar vertebral column in professional rowers (Hosea et al., 2011; Ogurkowska, 2007; Ogurkowska et al, 2016).

In the second examination, we noted a decrease in the concentration of total testosterone and the TT/C ratio, recognized as an anabolic/catabolic index. Other authors attributed such changes to body fatigue resulting from significant training loads (Ahtiainen et al., 2003). No significant changes in cortisol concentration and pro-inflammatory factors were observed in the study, which indicates that the decrease in the TT/C ratio value was probably not the result of the athletes' fatigue. In a study carried out on football players, Michailidis explained that the absence of changes in cortisol concentration in the annual training cycle was due to an appropriate psycho-physical preparation of the athletes (Michailidis, 2014). It is not impossible that the decrease in testosterone concentration was related to seasonal changes. In observational studies, Reinberg and Lagoguey (1978) showed that serum testosterone concentration in the annual cycle peaks in November. Moreover, in our study, despite the decrease in testosterone concentration in the second examination, we recorded an inverse correlation between TT/C and FT/C ratios and a change in the torque of the trunk extensor, which indicates that the slight changes in the mentioned hormone did not prevent the increase in muscle strength of the torso.

The decrease in creatine kinase activity between the two examinations proves that a higher load on muscle tissue engaged in the exercises occurred on the first examination. Creatine kinase activity depends on the duration and type of physical activity (Banfi et al., 2012). In particular, eccentric exercises lead to an increase in CK activity (Clarkson and Hubal, 2002; Nosaka and Clarkson, 1994). On the first examination the training of rowers was characterized by a larger volume and a significant share of strength training as compared to the second examination (Table 1), which may have had an impact on the changes in CK activity. It is also worth noting that on the second examination the global strength of the lower limbs decreased, which may be indicative of a decrease in the rowers' muscle mass engaged in the exercise, and which may also have had an impact on the changes in CK activity. Training adaptation resulting from the training program lasting several months could be an additional factor contributing to the decreased activity of this enzyme on the second examination of the study. 
280 Creatine kinase activity reflects the level of muscle fibre damage resulting from intense muscle

281

282

283

284

285

286

287

288

289

290

291

292

293

294

295

296

297

298

299

300

301

302

303

304

305

306

307

308

309

310

311

312

313

314

315

316

317

318

319

work and the rate of clearance of this enzyme from the blood. Elevated creatine kinase activity was observed for a few days after physical activity of sufficiently high intensity and duration. According to suggestions, the CK activity should preferably be measured 24 to 48 hours following physical activity (Banfi et al., 2012). In this study, blood was collected two days after the end of the last standard training session.

Release of CK from muscle cells during exercise corresponds to the degree of permeability of cell membranes and their damage resulting, among other things, from an increase in the amount of free radicals formed during physical activity, leading to the peroxidation of cell membrane lipids (Banfi et al., 2012; Masonet al., 2016). In our study we determined TBARS concentration reflecting the level of cell membrane damage. However, we did not find any significant changes in this indicator between the two examinations. At the same time, we observed a significant increase in the concentration of total phenolics, which are involved in scavenging of free radicals. In the data from the first examination, we found significant relationships between the concentration of these substances and some parameters of muscle strength (global strength of the left and right lower limb extensors and torque of right torso rotators), which may be indicative of their protective effect on skeletal muscle fibres. These substances in the circulatory system are an indicator of the amount of consumed foods which are rich in phenolic compounds and their absorption from the gastrointestinal tract (Scalbert and Williamson, 2000). Additionally, phenolic compounds have been shown to reduce muscle damage caused by increased ROS levels during physical exercise and restitution (Malaguti et al., 2013). It should be noted that total serum antioxidant capacity (FRAP) did not differ significantly between the two examinations, which means that the prooxidant-antioxidant balance was maintained despite significantly higher CK activity in the case of the first examination.

Reactive oxygen species produced during exercise may contribute to an intensified release of pro-inflammatory factors. In the study we measured levels of IL-6 and hsCRP. It is well known that cytokine levels may be induced by intense physical exercise from two to six days after exercise (Kasapis and Thompson, 2005; Pedersen and Hoffman-Goetz, 2000). An increase in IL6 concentration during muscle work is a result of two mechanisms: muscle contraction and muscle fibre damage. The level of increase in IL- 6 concentration after physical exercise depends on the type of exercise, intensity and duration as well as the mass of skeletal muscle engaged (Kasapis and Thompson, 2005). In our study, we found no significant changes in the indices on the second examination compared to the first examination, which means that the decrease in the strength of lower limb muscles on the second examination of the study was related to the training technique rather than overloading.

It has been shown that many immune cell functional responses may be modulated by carbohydrate status. Blood glucose is the fuel for cells of the immune system. The liver and muscle glycogen stores play the important role in minimising immunosuppression (Close et al., 2005). In our study, however, we did not report any relationships between the concentration of pro-inflammatory indices and carbohydrate metabolism indices (glucose, insulin or QUICKI).

PeerJ reviewing PDF | (2020:08:51684:1:0:NEW 11 Oct 2020) 
320 We also did not notice any significant changes between the examinations of the values of these

321

322

323

324

325

326

327

328

329

330

331

332

333

334

335

336

337

338

339

340

341

342

343

344

345

346

347

348

349

350

351

352

353

354

355

356

357

indices, which may be the result of high training adaptation of the athletes in terms of carbohydrate metabolism already on the first date of the examination. Training adaptation consists in improving the transport of glucose in the insulin-independent pathway (Egan and Zierath, 2013). This mechanism is influenced a.o. by testosterone, which activates the glucose metabolism-related signalling pathway in skeletal muscle cells via regulation of glucose transporter-4 (GLUT-4) (Sato et al., 2008). The decrease in TT level on the second examination correlated with the concentration of glucose and insulin, but it did not significantly affect QUICKI.

In the examinations, we determined the concentration of total phenolics which show antioxidant effects and are an indicator of intake of foods rich in these compounds. However, we did not include an analysis of the athletes' diet, which could document the influence of the consumed foods on the level of antioxidant potential and its importance in the training process.

\section{Conclusions}

The observed changes in biomechanical parameters during the training period show that technique-oriented training should be more focused on strengthening the athletes' lower limbs in order to protect the lumbar spine from overloading. It was also found that the amount of force developed is significantly related with the antioxidant potential of the body and we conclude that it may play a significant role in muscle strength. However, confirmation of this conclusion requires a larger group of subjects and representatives of various sports disciplines. Further studies are needed to investigate if there is a causality effect.

\section{Acknowledgements}

The authors would like to thank the athletes who took part in this study. The authors also would like to thank Ms. Magdalena Lewandowska for her assistance in the statistical analysis.

\section{References}

1. Ahtiainen JP, Pakarinen A, Kraemer WJ, Häkkinen K. 2003. Acute hormonal and neuromuscular responses and recovery to forced vs maximum repetitions multiple resistance exercises. International Journal of Sports Medicine 24:410-418 DOI: 10.1055/s-2003-41171

2. Banfi G, Colombini A, Lombardi G, Lubkowska A. 2012. Metabolic markers in sports medicine. Advances in Clinical Chemistry 56:1-54 DOI: 10.1016/b978-0-12-3943170.00015-7

3. Benzie IF, Strain JJ. 1966. The ferric reducing ability of plasma (FRAP) as a measure of "antioxidant power": the FRAP assay. Analytical Biochemistry 239:70-76 DOI: 10.1006/abio.1996.0292. 
358

359

360

361

362

363

364

365

366

367

368

369

370

371

372

373

374

375

376

377

378

379

380

381

382

383

384

385

386

387

388

389

390

391

392

393

394

395

4. Buśko K, Górski M, Nikolaidis PT, Mazur-Różycka J, Łach P, Staniak Z, Gajewski J. 2018. Leg strength and power in polish striker soccer players. Acta of Bioengineering and Biomechanics, 20:109-116 DOI: 10.5277/ABB-01066-2017-02.

5. Calmels PM, Nellen M, van der Borne I, Jourdin P, Minaire P. 1997. Concentric and eccentric isokinetic assessment of flexor-extensor torque ratios at the hip, knee, and ankle in a sample population of healthy subjects. Archives of Physical Medicine and Rehabilitation 78:1224-1230 DOI: 10.1016/s0003-9993(97)90336-1.

6. Clarkson PM, Hubal MJ. 2002. Exercise-induced muscle damage in humans. Archives of Physical Medicine and Rehabilitation 81:S52-69 DOI: 10.1097/00002060-20021100100007.

7. Close GL, Ashton T, Cable T, Doran D, Noyes C, McArdle F, MacLaren, DP. 2005. Effects of dietary carbohydrate on delayed onset muscle soreness and reactive oxygen species after contraction induced muscle damage. British Journal of Sports Medicine 39:948-953 DOI: 10.1136/bjsm.2005.019844.

8. Diamond LE, Wrigley TV, Hinman RS, Hodges PW, O’Donnell J, Takla A, Bennell KL. 2016. Isometric and isokinetic hip strength and agonist/antagonist ratios in symptomatic femoroacetabular impingement. Journal of Science and Medicine in Sport 19:696-701 DOI: 10.1016/j.jsams.2015.10.002.

9. Egan B, Zierath JR. 2013. Exercise metabolism and the molecular regulation of skeletal muscle adaptation. Cell Metabolism 17:162-184. DOI: 10.1016/j.cmet.2012.12.012.

10. Gee IT, Caplan N, Gibbon CK, Howatson G, Thompson GK. 2016. Investigating the effects of typical rowing strength training practices on strength and power development and 2,000 $\mathrm{m}$ rowing performance. Journal of Human Kinetics, 50:167-177 DOI: 10.1515/hukin-2015-0153.

11. Griggs RC, Kingston W, Jozefowicz RF, Herr BE, Forbes G, Halliday D. 1989. Effect of testosterone on muscle mass and muscle protein synthesis. Journal of Applied Physiology 66: 498-503 DOI: 10.1152/jappl.1989.66.1.498.

12. Hosea TM, Hannafin JA, Bran J, O'Hara D, Seufert P. 2011. Etiology of low back pain in athletes; role of sport type. British Journal of Sports Medicine 45:352 DOI: 10.1136/bjsm.2011.084038.120.

13. Hughes RE, Johnson ME, O'Driscoll SW, An KN. 1999. Normative values of agonistantagonist shoulder strength ratios of adults aged 20 to 78 years. Archives of Physical Medicine and Rehabilitation 80:1324-1326 DOI: 10.1016/s0003-9993(99)90037-0.

14. Janiak J, Wit A, Stupnicki R. 1993. Static muscle force in athletes practising rowing. Biology of Sport 10:29-34

15. Jensen J, Rustad PI, Kolnes AJ, Lai YC. 2011. The role of skeletal muscle glycogen breakdown for regulation of insulin sensitivity by exercise. Frontiers in Physiology 2:112 DOI: $10.3389 /$ fphys.2011.00112. 
396

397

398

399

400

401

402

403

404

405

406

407

408

409

410

411

412

413

414

415

416

417

418

419

420

421

422

423

424

425

426

427

428

429

430

431

432

433

16. Kabacinski J, Murawa M, Mackala K, Dworak LB. 2018. Knee strength ratios in competitive female athletes. PLoS One 13:e0191077 DOI: 10.1371/journal.pone.0191077.

17. Kasapis C, Thompson PD. 2005. The effects of physical activity on serum C-reactive protein and inflammatory markers: a systematic review. Journal of the American College of Cardiology 45:1563-1569 DOI: 10.1016/j.jacc.2004.12.077.

18. Katz A, Nambi SS, Mather K, Baron AD, Follmann DA, Sullivan G, Quon MJ. 2000. Quantitative insulin sensitivity check index: a simple, accurate method for assessing insulin sensitivity in humans. The Journal of Clinical Endocrinology and Metabolism 85:2402-2410 DOI: 10.1210/jcem.85.7.6661.

19. Kocjan A, Sarabon N. 2014. Assessment of isometric trunk strength - the relevance of body position and relationship between planes of movement. Journal of Sports Science and Medicine 13:365-370

20. Malaguti M, Angeloni C, Hrelia S. 2013. Polyphenols in exercise performance and prevention of exercise-induced muscle damage. Oxidative Medicine and Cellular Longevity 2013:825928 DOI: 10.1155/2013/825928.

21. Mason SA, Morrison D, McConell GK, Wadley GD. 2016. Muscle redox signalling pathways in exercise. Role of antioxidants. Free Radical Biology and Medicine 98:29-45 DOI: $10.1016 /$ j.freeradbiomed.2016.02.022.

22. McGregor A, Hill A, Grewar J. 2004. Trunk strength patterns in elite rowers. Isokinetics and Exercise Science 12:253-261 DOI: 10.3233/IES-2004-0183.

23. Michailidis Y. 2014. Stress hormonal analysis in elite soccer players during a season. Journal of Sport and Health Science 3:279-283 DOI: 10.1016/j.jshs.2014.03.016.

24. Nosaka K, Clarkson PM. 1994. Effect of eccentric exercise on plasma enzyme activities previously elevated by eccentric exercise. European Journal of Applied Physiology and Occupational Physiology 69:492-497 DOI: 10.1007/bf00239865.

25. Ogurkowska MB, Lewandowski J, Kawałek K. 2016. Geometric parameters of the lumbosacral spine in elite rowers. Medicina dello Sport 69:422-434

26. Ogurkowska MB. 2007. Pathological changes in lumbar-sacral intervertebral discs in professional rowers. Biology of Sport 24:375-388

27. Ogurkowska MB, Kawałek K, Zygmańska M. 2015. Biomechanical characteristics of rowing. Trends in Sports Science 2:61-69

28. Ohkawa H, Ohishi N, Yagi K. 1979. Assay for lipid peroxides in animal tissues by thiobarbituric acid reaction. Analytical Biochemistry 95:351-358 DOI: 10.1016/00032697(79)90738-3.

29. Pedersen BK, Hoffman-Goetz L. 2000. Exercise and the immune system: regulation, integration, and adaptation. Physiological Reviews 80:1055-1081 DOI: 10.1152/physrev.2000.80.3.1055.

PeerJ reviewing PDF | (2020:08:51684:1:0:NEW 11 Oct 2020) 
434

435

436

437

438

439

440

441

442

443

444

445

446

447

448

449

450

451

452

453

454

455

456

457

458

459

460

461

462

463

464

30. Reinberg A, Lagoguey M. 1978. Circadian and circannual rhythms in sexual activity and plasma hormones (FSH, LH, Testosterone) of five human males. Archives of Sexual Behavior 7:13-30 DOI: 10.1007/bf01541895.

31. Richter C, Hamilton S, Roemer K. Influence of body mass index on rowing kinematics. $28^{\text {th }}$ International Symposium on Biomechanics in Sports 2010.

32. Sass FA, Fuchs M, Pumberger M, Geissler S, Duda GN, Perka C, Schmidt-Bleek K. 2018. Immunology guides skeletal muscle regeneration. International Journal of Molecular Sciences 19:pii:E835 DOI: 10.3390/ijms19030835.

33. Sato K, Iemitsu M, Aizawa K, Ajisaka R. 2008. Testosterone and DHEA activate the glucose metabolism-related signaling pathway in skeletal muscle. American Journal of Physiology-Endocrinology and Metabolism 294:E961-968 DOI: 10.1152/ajpendo.00678.2007.

34. Scalbert A, Williamson G. 2000. Dietary intake and bioavailability of polyphenols. Journal of Nutrition 130:2073S-2085S DOI: 10.1093/jn/130.8.2073S.

35. Singleton VL, Rossi JA. 1965. Colorimetry of total phenolics with phosphomolybdicphosphotungstic acid reagents. American Journal of Enology and Viticulture 16:144-158

36. Steinbacher P, Eckl P. 2015 Impact of oxidative stress on exercising skeletal muscle. Biomolecules 5:356-377 DOI: 10.3390/biom5020356.

37. Sterkowicz S, Lech G, Sterkowicz-Przybycień K, Chwała W, Ambroży T, Pałka T. 2018. Relationship of maximal isometric torque produced in flexors and extensors rate to technique by judo athletes. Acta of Bioengineering and Biomechanics 20:65-71 DOI: 10.5277/ABB-01100-2018-02.

38. Tidball JG. 2005. Inflammatory processes in muscle injury and repair. American Journal of Physiology-Regulatory, Integrative and Comparative Physiology 288:R345-353 DOI: 10.1152/ajpregu.00454.2004.

39. Woods AL, Garvican-Lewis LA, Lundy B, Rice AJ, Thompson KG. 2017. New approaches to determine fatigue in elite athletes during intensified training: Resting metabolic rate and pacing profile. PLoS One 12:e0173807 DOI: 10.1371/journal.pone.0173807.

40. Yang W, Hu P. 2018. Skeletal muscle regeneration is modulated by inflammation. Journal of Orthopaedic Translation 13:25-32 DOI: 10.1016/j.jot.2018.01.002. 


\section{Table 1 (on next page)}

Rowers' weekly training frequency in a macrocycle (training load description) 
1 Table 1. Rowers' weekly training frequency in a macrocycle (training load description)

\begin{tabular}{|c|c|c|c|c|c|c|}
\hline $\begin{array}{l}\text { Training } \\
\text { objective }\end{array}$ & Week & Method & Training modality & $\begin{array}{l}\text { Duration } \\
\text { (min.) }\end{array}$ & $\begin{array}{l}\text { Intensity } \\
(\% \max )\end{array}$ & $\begin{array}{l}\text { No. of } \\
\text { training } \\
\text { sessions } \\
\text { per week }\end{array}$ \\
\hline \multirow{6}{*}{$\begin{array}{l}\text { Aerobic } \\
\text { endurance } \\
\text { (maintenance) }\end{array}$} & $1-4$ & constant & $\begin{array}{l}\text { running, indoor rower, } \\
\text { swimming }\end{array}$ & $100-125$ & 60 & 5 \\
\hline & $5-8$ & constant & running, indoor rower & $100-125$ & 60 & 3 \\
\hline & $9-12$ & constant & indoor rower, running & $80-120$ & $60-65$ & 3 \\
\hline & $13-16$ & constant/variable & indoor rower & $80-90$ & $60-65$ & 3 \\
\hline & $17-20$ & constant/variable & $\begin{array}{l}\text { running, indoor rower, } \\
\text { boat rowing }\end{array}$ & $60-90$ & $60-65$ & $3-4$ \\
\hline & $21-24$ & constant/variable & boat rowing/running & $60-80$ & $60-65$ & 2 \\
\hline \multirow{5}{*}{$\begin{array}{l}\text { Aerobic } \\
\text { endurance } \\
\text { (development) }\end{array}$} & $5-8$ & constant/variable & $\begin{array}{l}\text { running, bike, swimming, } \\
\text { indoor rower, cross- } \\
\text { country skiing }\end{array}$ & $100-120$ & $65-70$ & 2 \\
\hline & $9-12$ & constant/variable & running, indoor rower & $90-110$ & $65-70$ & 2 \\
\hline & $13-16$ & constant/variable & running, indoor rower & $90-110$ & $65-75$ & 2 \\
\hline & $17-20$ & constant/variable & indoor rower/boat rowing & $90-100$ & $65-75$ & $1-2$ \\
\hline & $21-24$ & constant/variable & boat rowing/running & 60 & $65-75$ & 1 \\
\hline \multirow{5}{*}{$\begin{array}{l}\text { Aerobic- } \\
\text { anaerobic } \\
\text { endurance }\end{array}$} & $5-8$ & long interval & running, indoor rower & $20-30$ & $65-75$ & 1 \\
\hline & $9-12$ & long interval & indoor rower & 30 & $65-80$ & 1 \\
\hline & $13-16$ & long interval & indoor rower & 30 & $70-85$ & 2 \\
\hline & $17-20$ & $\begin{array}{l}\text { variable/long } \\
\text { interval }\end{array}$ & $\begin{array}{l}\text { indoor rower, boat } \\
\text { rowing }\end{array}$ & $30-60$ & $75-85$ & 2 \\
\hline & $21-24$ & long interval & boat rowing & $30-40$ & $65-80$ & 2 \\
\hline $\begin{array}{l}\text { Anaerobic } \\
\text { endurance }\end{array}$ & $21-24$ & short interval & boat rowing & $20-30$ & $75-90$ & 2 \\
\hline $\begin{array}{l}\text { Muscle mass - } \\
\text { hypertrophy }\end{array}$ & $1-4$ & body building & strength exercises & 120 & $60-80$ & 3 \\
\hline $\begin{array}{l}\text { Maximum } \\
\text { strength }\end{array}$ & $5-8$ & strength athletics & strength exercises & 120 & $95-100$ & 3 \\
\hline \multirow{3}{*}{$\begin{array}{l}\text { Strength } \\
\text { endurance }\end{array}$} & $13-16$ & circuit training & & $90-110$ & $50-60$ & 2 \\
\hline & $17-20$ & circuit training & strength exercises & $90-110$ & $50-60$ & 2 \\
\hline & $21-24$ & circuit training & & $45-60$ & $50-60$ & 2 \\
\hline \multirow{3}{*}{ Power } & $9-12$ & \multirow{3}{*}{ strength-speed } & \multirow{3}{*}{ strength exercises } & 100 & $60-70$ & 3 \\
\hline & $13-20$ & & & 100 & $60-70$ & 1 \\
\hline & $21-24$ & & & 45 & $60-70$ & 1 \\
\hline $\begin{array}{l}\text { Deep muscle } \\
\text { training }\end{array}$ & $1-12$ & repetition & $\begin{array}{l}\text { exercises with various } \\
\text { beams, balance } \\
\text { exercises, etc. }\end{array}$ & 30 & - & $1-2$ \\
\hline Team sports & $1-20$ & variable & football, volleyball & $30-60$ & $60-70$ & 2 \\
\hline
\end{tabular}

2 Intensity \% $\mathrm{VO}_{2} \mathrm{max}$, strength training: \% 1RM 


\section{Table 2 (on next page)}

Somatic indices during first and second examination in groups of rowers, mean (SD); median (interquartile range) 
1 Table 2. Somatic indices during first and second examination in groups of rowers $(n=17)$, mean 2 (SD); median (interquartile range)

\begin{tabular}{|c|c|c|}
\hline Parameters & $\begin{array}{l}\text { Assessment } \\
\text { First examination }\end{array}$ & $\begin{array}{l}\text { Assessment } \\
\text { Second examination }\end{array}$ \\
\hline Age (yrs) & \multicolumn{2}{|c|}{$22.23(4.58) ; 20.0(20.0-23.0)$} \\
\hline Training experience (yrs) & \multicolumn{2}{|c|}{$9.35(4.45) ; 8.0(7.00-11.0)$} \\
\hline Body height (m) & \multicolumn{2}{|c|}{$1.93(0.06) ; 1.92(1.89-1.94)$} \\
\hline Body mass (kg) & $93.65(8.80) ; 92.1(88.5-98.0)$ & $93.49(7.78) ; 92.0(90.5-98.4)$ \\
\hline Fat mass $(\%)$ & $13.28(3.67) ; 11.4(10.4-16.0)$ & $12.57(3.47) ; 12.2(11.4-13.9)$ \\
\hline Fat mass $(\mathrm{kg})$ & $12.50(4.01) ; 10.5(10.0-14.0)$ & $11.74(3.48) ; 11.0(10.7-12.8)$ \\
\hline Fat free mass $(\mathrm{kg})$ & $81.15(7.71) ; 81.6(78.5-84.6)$ & $81.77(7.64) ; 81.8(78.3-84.8)$ \\
\hline
\end{tabular}

3 


\section{Table 3 (on next page)}

Biomechanical indices during first and second examination in groups of rowers $(n=17)$, mean (SD); median (interquartile range 
1 Table 3. Biomechanical indices during first and second examination in groups of rowers $(\mathrm{n}=$ 2 17), mean (SD); median (interquartile range)

\begin{tabular}{|c|c|c|}
\hline \multirow{2}{*}{ Parameters } & Assessment & Assessment \\
\hline & First examination & Second examination \\
\hline $\begin{array}{l}\text { Global strength of lower limb } \\
\text { extensors, left }(\mathrm{N} / \mathrm{kg})\end{array}$ & $31.8(6.8) ; 29.7(25.5-37.1)$ & $29.8(5.1) ; 29.4(25.5-34.4)$ \\
\hline $\begin{array}{l}\text { Global strength of lower limb } \\
\text { extensors, right }(\mathrm{N} / \mathrm{kg})\end{array}$ & $31.3(5.3) ; 30.8(27.5-34.6)$ & $28.6(3.5) ; 28.3(25.9-31.4)^{*, \mathrm{a}}$ \\
\hline $\begin{array}{l}\text { Torques - torso, extensors } \\
(\mathrm{Nm} / \mathrm{kg})\end{array}$ & $7.06(1.30) ; 6.89$ (6.25-7.93) & 7.45 (1.09); 7.31 (6.80-7.70) \\
\hline $\begin{array}{l}\text { Torques - torso, flexors } \\
(\mathrm{Nm} / \mathrm{kg})\end{array}$ & $3.44(0.31) ; 3.41(3.20-3.54)$ & $3.80(0.33) ; 3.69(3.56-3.97)^{*, b}$ \\
\hline $\begin{array}{l}\text { Torques - torso rotators, left } \\
(\mathrm{Nm} / \mathrm{kg})\end{array}$ & $1.46(0.25) ; 1.46(1.31-1.71)$ & $1.39(0.31) ; 1.42(1.20-1.61)$ \\
\hline $\begin{array}{l}\text { Torques - torso rotators, right } \\
(\mathrm{Nm} / \mathrm{kg})\end{array}$ & $1.33(0.24) ; 1.32(1.16-1.40)$ & $1.24(0.26) ; 1.18(1.10-1.33)^{*, a}$ \\
\hline
\end{tabular}


Table 4 (on next page)

Biochemical indices during first and second examination in groups of rowers $(n=17)$, mean (SD); median ( interquartile range ) 
1 Table 4. Biochemical indices during first and second examination in groups of rowers $(\mathrm{n}=17)$, 2 mean (SD); median (interquartile range)

\begin{tabular}{lll}
\hline Parameters & $\begin{array}{l}\text { Assessment } \\
\text { First examination }\end{array}$ & $\begin{array}{l}\text { Assessment } \\
\text { Second examination }\end{array}$ \\
\hline hsCRP $(\mathrm{mg} / \mathrm{L})$ & $0.19(0.07) ; 0.18(0.15-0.22)$ & $0.16(0.09) ; 0.15(0.07-0.23)$ \\
IL-6 $(\mathrm{ng} / \mathrm{mL})$ & $0.09(0.05) ; 0.07(0.07-0.10)$ & $0.09(0.05) ; 0.07(0.06-0.11)$ \\
Insulin $(\mu \mathrm{U} / \mathrm{mL})$ & $10.34(2.37) ; 9.81(8.83-10.93)$ & $9.89(2.29) ; 9.36(8.01-10.70)$ \\
Glucose $(\mathrm{mg} / \mathrm{dL})$ & $96.18(6.73) ; 97.0(90.0-100.0)$ & $95.29(8.35) ; 96.0(93.0-102.0)$ \\
QUICKI & $0.34(0.01) ; 0.34(0.33-0.34)$ & $0.34(0.01) ; 0.34(0.33-0.34)$ \\
CK $(\mathrm{U} / \mathrm{L})$ & $437.1(313.9) ; 313.1(209.7-480.5)$ & $266.1(174.1) ; 208.1(154.9-275.8)^{*, \mathrm{~b}}$ \\
C $(\mathrm{ng} / \mathrm{mL})$ & $315.5(191.3) ; 253.4(235.1-294.8)$ & $292.7(90.9) ; 274.5(229.6-331.8)$ \\
TT $(\mathrm{ng} / \mathrm{mL})$ & $5.74(1.13) ; 5.54(4.97-6.29)$ & $5.21(1.27) ; 5.17(4.45-5.59) *, \mathrm{~b}$ \\
FT $(\mathrm{pg} / \mathrm{mL})$ & $16.31(4.06) ; 15.88(13.36-17.95)$ & $16.43(4.54) ; 15.55(13.33-18.94)$ \\
TT/C & $0.023(0.010) ; 0.02(0.018-0.025)$ & $0.020(0.008) ; 0.02(0.014-0.023)^{*, \mathrm{a}}$ \\
FT/C & $0.065(0.031) ; 0.07(0.053-0.074)$ & $0.061(0.025) ; 0.06(0.045-0.069)$ \\
FRAP $(\mu \mathrm{mol} / \mathrm{L})$ & $861.0(146.6) ; 828.5(762.4-938.3)$ & $855.6(160.2) ; 872.0(764.6-938.6)$ \\
Total phenolics $(\mathrm{g} \mathrm{GAE} / \mathrm{L})$ & $2.51(0.10) ; 2.50(2.42-2.57)$ & $2.59(0.16) ; 2.61(2.54-2.64)^{*, \mathrm{a}}$ \\
TBARS $(\mu \mathrm{mol} / \mathrm{L})$ & $4.54(1.12) ; 4.16(3.93-5.17)$ & $4.10(0.97) ; 3.87(3.38-4.45)$ \\
\hline Abbreviations: & & \\
\hline
\end{tabular}

3 Abbreviations: hsCRP $=$ high sensitivity C-reactive protein, IL-6 = human interleukin-6, 4 QUICKI = Quantitative Insulin Sensitivity Check Index, CK = creatine kinase, $\mathrm{C}=$ cortisol, TT $5=$ total testosterone, FT $=$ free testosterone, FRAP = Ferric Reducing Ability of Plasma, GAE = 6 gallic acid equivalent, TBARS $=$ thiobarbituric acid reactive substances.

7 * indicates a significant difference $(\mathrm{p}<0.05) ;{ }^{\mathrm{a}} T$-test; ${ }^{\mathrm{b}}$ Wilcoxon test 
Figure 1

Measurement of global force of lower limb extensors in a sitting position. The torso is inclined at an angle of $30^{\circ}$ from the vertical. Characteristic thigh-calf angle: $135^{\circ}$. The backrest of the foot pedals was inclined at an $75^{\circ}$ angle. The pelvis is stabi 

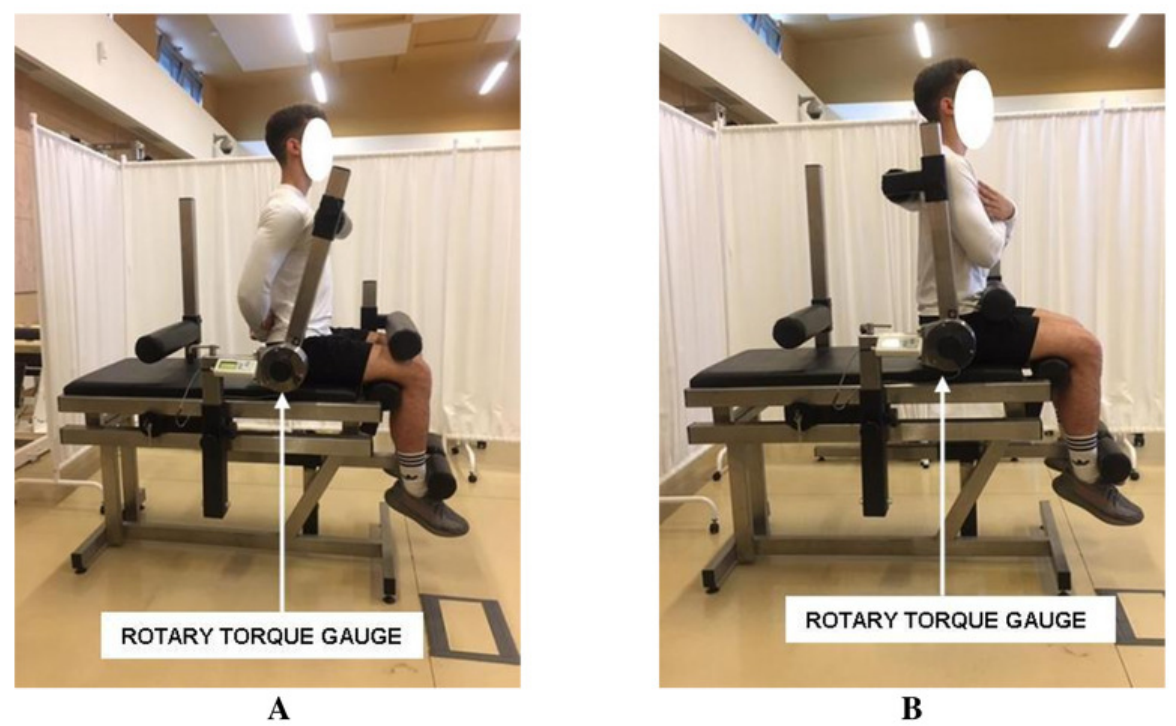

Figure 1. Measurement of torque of torso flexors (A) and extensors (B) in a seated position. Characteristic torso-thigh angle: $90^{\circ}$. The axis of the torque head is set in the line of the axis of rotation of the hip joint. 
Figure 2

Measurement of torque of torso rotators muscles in a seated position. The torque is determined relative to the vertical axis of the spine. 


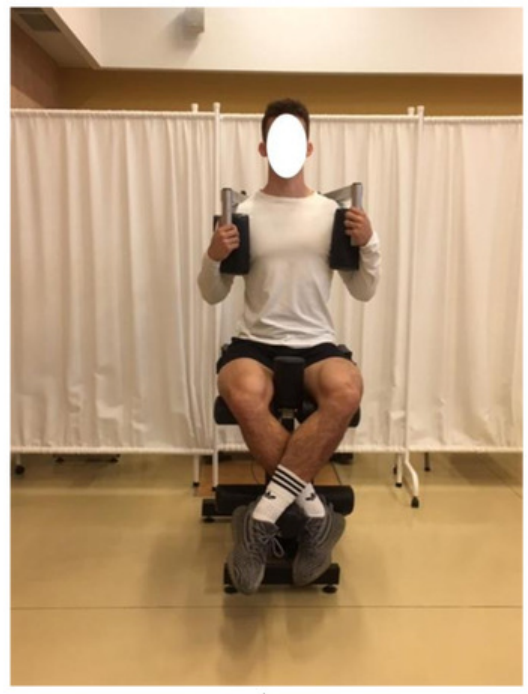

A

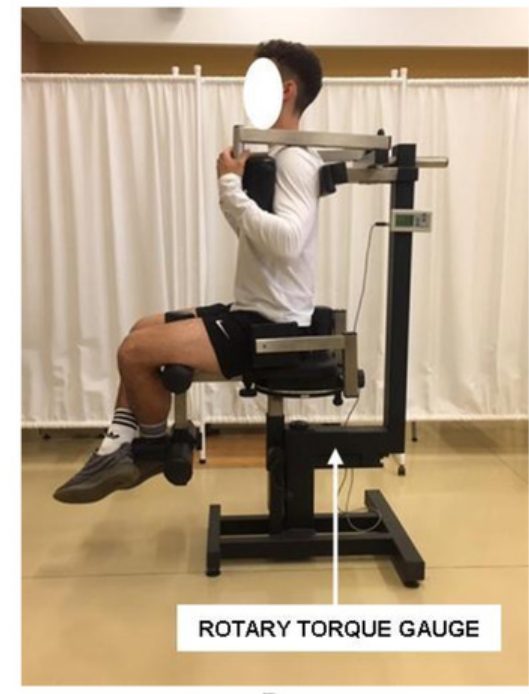

B

Figure 2. Measurement of torque of torso rotators muscles in a seated position. The torque is determined relative to the vertical axis of the spine. 
Figure 3

Measurement of torque of torso flexors (A) and extensors (B) in a seated position. Characteristic torso-thigh angle: $90^{\circ}$. The axis of the torque head is set in the line of the axis of rotation of the hip joint. 


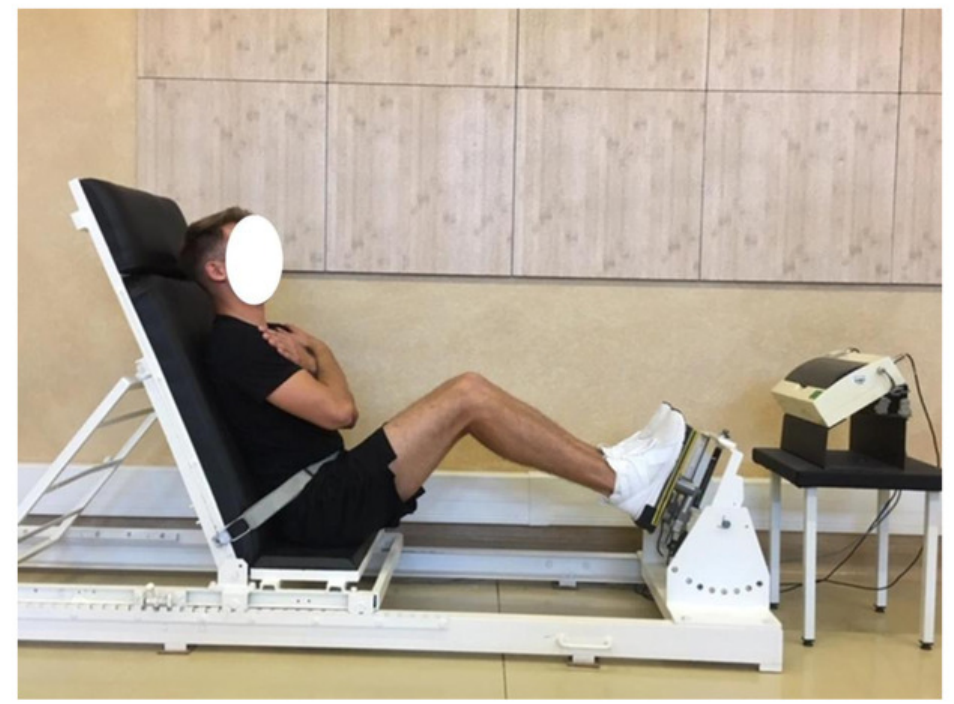

Figure 3. Measurement of global force of lower limb extensors in a sitting position. The torso is inclined at an angle of $30^{\circ}$ from the vertical. Characteristic thigh-calf angle: $135^{\circ}$. The backrest of the foot pedals was inclined at an $75^{\circ}$ angle. The pelvis is stabilized on the seat with the use of belts. 
Figure 4

Correlations of the total phenolics concentration with the global strength of extensors of lower limbs and the torque of right torso rotators in the first examination $\left(4 \mathrm{~A}^{1}\right.$ and $4 \mathrm{~B}^{1}$, respectively) and correlation of the change between tw 


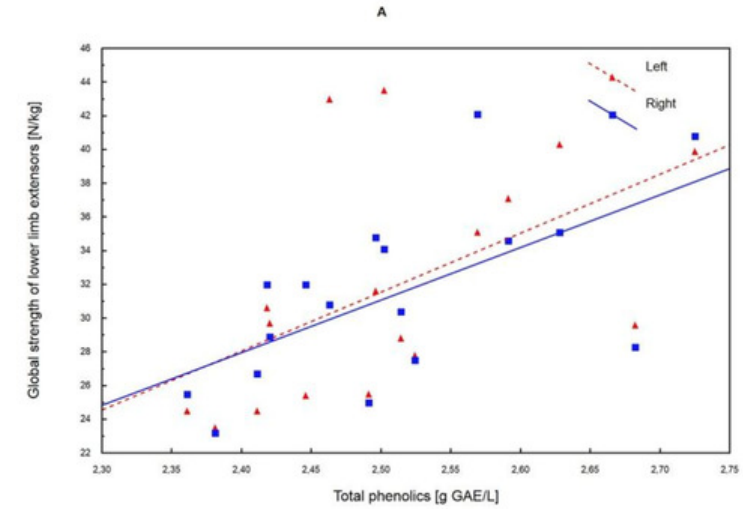

B

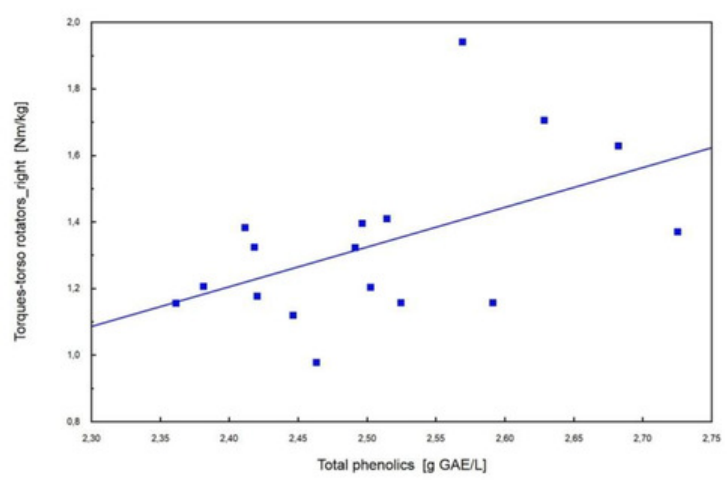

c

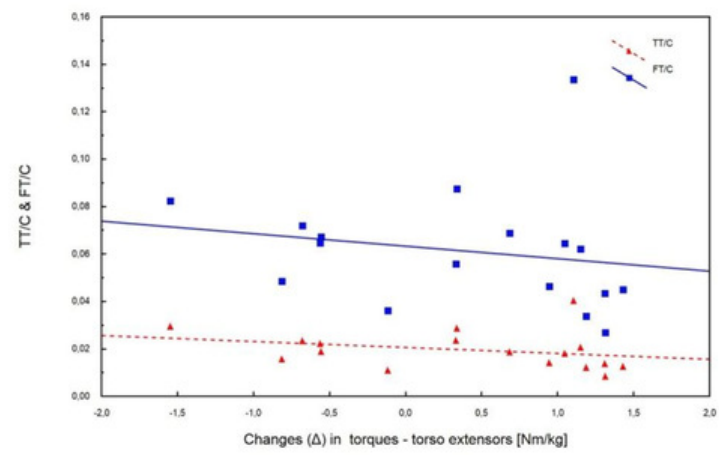

Figure 4. Correlations of the total phenolics concentration with the global strength of extensors of lower limbs and the torque of right torso rotators in the first examination ( $4 \mathrm{~A}^{1}$ and $4 \mathrm{~B}^{1}$, respectively) and correlation of the change between two examinations $(\Delta)$ in the trunk extensors torque with total (TT) and free (FT) to cortisol (C) ratios (TT/C and FT/C) in the second examination $\left(4 \mathrm{C}^{2}\right) .{ }^{1}$ Pearson correlation; ${ }^{2}$ Spearman's rank correlation 